\title{
Ambientes e Produtos Homeodinâmicos: perspectivas e contribuições à saúde e ao bem- estar do ser humano
}

Rachel Zuanon é Artista midiática e designer. Docente no Curso de Artes Visuais e professora/pesquisadora junto às áreas de Processo Criativo em Composição Artística e de Arte e Tecnologia (IA-UNICAMP). Professora e pesquisadora do PPG-AV (IA-UNICAMP) e do PPG-ATC (FEC-UNICAMP). Cofundadora e cocoordenadora da DASMind-UNICAMP [Design, Art, Space and Mind: Transdisciplinary Cooperation Network in Research and Innovation]. Coordenadora de Pesquisa e Extensão (IA UNICAMP). Coordenadora do LIS (IA-UNICAMP). Membro do Conselho da GAIA (Galeria de Arte/IA-UNICAMP). Com prêmios nacionais e internacionais, desde 1998, dedica sua pesquisa e produções à cooperação Neurociência e Processos Criativos e Projetuais. <rzuanon@unicamp.br> ORCID: 0000-0002-7917-9917
Resumo Pela perspectiva da homeodinâmica (ROSE, 1998), os processos de regulação da vida, e o decorrente equilíbrio alcançado, se elaboram em um fluxo dinâmico e em contínua transformação, diferente da possível ideia de um equilíbrio fixo e imutável. Alinhado a esta perspectiva, está o conceito dos "Ambientes e Produtos Homeodinâmicos", cunhado pelos cofundadores da Rede de Cooperação Transdisciplinar em Pesquisa e Inovação DASMind | UNICAMP [Design, Art, Space and Mind], também autores deste artigo. 0 referido conceito é sediado nos campos das artes, da arquitetura, do urbanismo, e do design, e parte de uma abordagem transdisciplinar e complexa, para compreender a concepção, o projeto, o planejamento, o desenvolvimento e a implantação de ambientes arquitetônicos e urbanos, bem como de produtos físicos e/ou digitais, em profunda sinergia com a esfera corpo-mente-espiritualidade dos indivíduos. Trata-se de assumir os ambientes e os objetos como importantes atores nesse contínuo e dinâmico processo de ajustamento interno do corpo. Como instrumentos homeodinâmicos, preventivos e restauradores da saúde e do bem-estar, estes ambientes e produtos, para além de uma participação passiva na vida humana, são projetados para atuar de modo consistente e dinâmico sobre o organismo humano.

Palavras chave Ambientes Arquitetônicos Homeodinâmicos; Ambientes Urbanos Homeodinâmicos; Produtos Homeodinâmicos Físicos e/ou Digitais; Transdisciplinaridade. 


\section{Homeodynamic Environments and Products: perspectives and contributions to hu-} man health and well-being

Claudio Lima Ferreira é Arquiteto, urbanista e pedagogo, professor do Programa de Pós-graduação em Arquitetura, Tecnologia e Cidade, da FEC-UNICAMP. Pós-Doutorado em Arquitetura e Urbanismo pela Universidade Presbiteriana Mackenzie, Doutorado pela UNICAMP, Mestrado pela PUC-Campinas e Especialização em Ensino Superior pela Universidade Anhembi Morumbi. No período 2017-2020, foi coordenador associado do Curso de Artes Visuais, do IA-UNICAMP. Cofundador e cocoordenador da DASMind-UNICAMP [Design, Art, Space and Mind: Transdisciplinary Cooperation Network in Research and Innovation]. <limacf@unicamp.br>

ORCID: 0000-0001-8345-5091
Abstract From the homeodynamics' perspective (ROSE, 1998), the life regulation processes, and the resulting balance achieved, are elaborated in a dynamic flow and in continuous transformation. That differs from the possible idea of a fixed and immutable balance. In line with this perspective, stands out the concept of "Homeodynamic Environments and Products", coined by the co-founders of the DASMind [Design, Art, Space and Mind] - UNICAMP Transdisciplinary and Cooperative Research and Innovation network, also authors of this article. This concept is based in the fields of arts, architecture, urban design/planning, and visual/product design. Always in a transdisciplinary and complex approach, this concept seeks to understand the conception, design, planning, development and implantation of architectural and urban environments, as well as physical and/ or digital products, in deep synergy with the individuals' body-mind-spirituality sphere. Environments and objects become important actors in the body's continuous and dynamic internal adjustment process. As preventive and restorative for health and well-being, the homeodynamic environments and products are not designed merely as passive elements, but otherwise to act consistently and dynamically on the human organism.

Keywords Homeodinamic Architectural Environments; Homeodynamic Urban Environments; Homeodynamic Physical and/or Digital Products; Transdisciplinarity. 


\section{Ambientes y productos homeodinámicos: perspectivas y contribuciones a la salud y el bienestar humanos}

Evandro Ziggiatti Monteiro é Arquiteto e Urbanista, professor do Programa de Pós-Graduação em Arquitetura, Tecnologia e Cidade, da FEC-UNICAMP. Suas pesquisas estão relacionadas à morfologia urbana, suas mudanças e impactos na paisagem urbana. Entre 2013 e 2016 foi coordenador do Curso de Arquitetura e Urbanismo da UNICAMP. Desde 2010, é coordenador associado do FLUXUS, Laboratório de Ensinagem em Redes Técnicas e Sustentabilidade Socioambiental. Cofundador e cocoordenador da DASMind UNICAMP [Design, Art, Space and Mind: Transdisciplinary Cooperation Network in Research and Innovation]. <evandrozig@fec.unicamp.br> ORCID: 0000-0002-6304-1614
Resumen Por la perspectiva de la homeodinámica (ROSE, 1998), los procesos de regulación de la vida, y el debido equilibrio alcanzado, se elaboran en un flujo dinámico y en transformación continua, diferente a la posible idea de un equilibrio fijo e inmutable. En línea con esta perspectiva, se encuentra el concepto de "Ambientes y Productos Homeodinámicos", acuñado por los cofundadores de la Red de Cooperación Transdisciplinar en Investigación e Innovación DASMind I UNICAMP [Diseño, Arte, Espacio y Mente], también autores de este artículo. Este concepto se basa en los campos de las artes, la arquitectura, el urbanismo y el diseño, y parte de un enfoque transdisciplinario y complejo, para comprender la concepción, proyecto, planificación, desarrollo e implantación de ambientes arquitectónicos y urbanos, así como productos físicos y/o digitales, en profunda sinergia con el ámbito cuerpo-mente-espiritualidad de los individuos. Se trata de asumir ambientes y objetos como actores importantes en este proceso continuo y dinámico de ajuste interno del cuerpo. Como instrumentos homeodinámicos, preventivos y restauradores para la salud y el bienestar, estos ambientes y productos, más allá de la participación pasiva en la vida humana, están proyectados para actuar de forma coherente y dinámica sobre el organismo humano.

Palabras clave Ambientes Arquitectónicos Homeodinámicos; Ambientes Urbanos Homeodinámicos; Productos Homeodinámicos Fisicos y/o Digitales; Transdisciplinariedad. 


\section{Da humanização às ambiências humanizadas}

Os conceitos humanizadores começam a ser discutidos enquanto pensamento e prática projetual em meados do século XX, especialmente motivados pelas áreas de estudo da sociologia, da antropologia e da psicologia ambiental. Admitido por Robert Sommer em 1974, o termo 'humanização' focaliza as necessidades globais do usuário (biológicas, psicológicas e sociais), o que implica em uma abordagem inter e transdisciplinar nas suas múltiplas dimensões: conceitual, metodológica, projetual e construtiva. Por outro lado, seu significado, ainda hoje, mostra-se em contínua elaboração. Não há um consenso na literatura acerca do significado da humanização. $\mathrm{Na}$ realidade, observa-se a coexistência de conceitos híbridos que, até o presente momento, servem de balizadores às iniciativas projetuais alinhadas aos seus preceitos. À parte as especificidades de cada perspectiva, todas são unânimes na valorização do usuário, do que é imprescindível ao seu bem-estar, e do seu envolvimento no processo projetual (KOWALTOWSKI, 1998; CAVALCANTI et al., 2007; LUKIANTCHUKI E SOUZA, 2010; LEITNER et al., 2020). A este eixo estrutural, destacam-se a seguir os principais entendimentos que têm delineado este conceito.

A humanização considera a relação do ser humano com o seu ambiente como um processo interativo, ou seja, de reciprocidade dirigida à aproximação, à apropriação e à identificação do usuário com o espaço físico. Ou seja, trata-se de um processo que descarta a visão projetual unidirecional, com imposições construtivas ao ser humano. Contrário disso, a abertura ao diálogo se coloca na possibilidade de personalização dos espaços por seus usuários, o que estabelece um processo mútuo e recíproco entre ambos. Os usuários conferem aos espaços qualidades que vão ao encontro das suas necessidades somatossensoriais, territoriais, de segurança e privacidade, de localização e orientação espacial, valores estéticos, entre outras, o que favorece seu uso e apropriação pelos seres humanos. (BARROS E KOWALTOWSKI, 2013). No sentido inverso, adaptados pela ação dos usuários, os lugares tornam-se vivos, receptivos aos anseios humanos. Essa simbiose garante a qualificação dos espaços: permuta-se sua qualidade original, como espaços neutros, para espaços humanizados. Uma vez humanizados, os lugares acolhem os indivíduos de forma harmoniosa. Configuram ambientes que permitem e estimulam a manifestação plena de suas identidades individual e coletiva. Em retorno, os indivíduos mantêm o cuidado e a constante readequação dos ambientes, pois os consideram seus. Este processo de interação espaço-indivíduo somente faz sentido quando associado ao conceito de ambiência (MALLARD, 1993). 
Por meio de áreas do conhecimento como a geografia, a engenharia e a arquitetura, design, aprendemos a separar as características físico-funcionais do espaço, e eventualmente nos esquecemos que os espaços, os ambientes e os objetos que os compõem só possuem significado a partir do próprio referencial humano (PALLASMAA, 2013). Eles congregam a vida, com suas experiências públicas e íntimas (POL, E., 1992). Repletos de sons, aromas, luzes, cores, figuras, formas, temperaturas, os espaços, ambientes e objetos são sentidos em nosso próprio corpo (DUARTE, 2013), o que resulta na sua apropriação como parte de nossa identidade. A ambiência é o resultado da consciência sobre esses processos de experiência e de interação e, simultaneamente, dos espaços e lugares que lhes dão suporte (DUARTE, 2013). Desta forma, cada local adquire uma ambiência própria, cuja base é composta por uma miríade de fatores visíveis e invisíveis que o impregnam de forma articulada - definem sua identidade e influenciam o comportamento de seus habitantes e transeuntes. Cotidianamente em construção, a ambiência é composta por aspectos físicos, culturais, sociais, de uso, de temporalidade, entre outros, sendo que nem todos são acessados pela consciência. (THIBAUD, 2004). O termo tem origem no francês "ambiance", o que lhe confere um significado mais amplo que simplesmente ambiente, ou o espaço percebido. Embora a questão da percepção seja um dos conceitos-chave para o entendimento da ambiência, isso envolve um processo complexo, que correlaciona características pessoais, motivação e experiência anteriores, os quais estão relacionados à maior ou à menor sensibilidade do indivíduo ao espaço. (TUAN, 1980).

Mas se consideramos ambiência como algo intrínseco ao conceito de humanização (MALLARD, 1993), faz sentido pensar em "ambiências humanizadas"? Julgamos que sim. A ambiência, compreendida como o conjunto das sensações, experiências, memórias e sentimentos ligados ao contexto sócio-físico, cultural e temporal vivenciado pela pessoa com relação a um lugar pode, portanto, ocorrer na forma de uma experiência negativa, de um espaço hostil ao seu uso e apropriação, por exemplo (TUAN, 1980-2005). Em outras palavras, a ambiência é um fenômeno da percepção humana de um espaço, cuja natureza pode não ser a mais adequada e saudável para o ser humano. Ou seja, a ambiência percebida pode ser positiva, ou negativa, dependendo da natureza, dos elementos e das qualidades do espaço. E estes são aspectos possíveis de serem avaliados, investigados, e generalizados, uma vez que as necessidades humanas denotam certas afinidades, as quais são válidas para a humanidade ao longo da sua história. Embora socialmente construídas, tais afinidades permanecem, em certos vieses, nas diferenças grupais e temporais (KOHLSDORF E KOHLSDORF, 2017). O adjetivo "humanizadas" retira das ambiências a sua neutralidade conceitual, e nos permite concentrar esforços na compreensão das características do ambiente e dos processos interativos entre as pessoas e o espaço, com foco nas qualidades 
espaciais que favorecem e enriquecem essa interação. Ou seja, ao adentrarmos o universo das ambiências humanizadas, reconhecemos os aspectos e os processos positivos que favorecem os diversos níveis de interação das pessoas com o ambiente que as cerca, seja na escala individual ou coletiva.

Por meio da consciência, o ser humano demonstra expressiva adaptabilidade, o que lhe confere a capacidade de criar novas soluções para os problemas da vida e para a sua sobrevivência, em praticamente qualquer ambiente, no planeta e até mesmo fora dele (DAMÁSIO, 2011). É justamente o engenho da mente humana que justifica e dá sentido à proposta de ambiências humanizadas. Ao se tornar hegemônica no planeta terra, a espécie humana distende suas necessidades, pensamentos, sentimentos e desejos como expectativas projetadas na configuração, na qualidade e no desempenho dos lugares e dos objetos. Ou seja, desde tempos imemoriais, o ser humano se dedica à atividade de transformar seu ambiente, adaptando-o aos seus anseios. Em um nível mais básico, isto sempre representou economia de energia e de recursos para cumprir o grande objetivo da sobrevivência.

A semente da inquietação que trazemos aqui liga, portanto, dois grandes axiomas. $\mathrm{O}$ primeiro, é a incansável predisposição humana para a interação com o ambiente externo, transformando os lugares e os objetos para melhor servirem à espécie, humanizando-os. E o segundo, é a sua estrutura biológica que, por meio dos processos metabólicos de regulação da vida, busca o permanente equilíbrio interno do indivíduo, sem prescindir de sua interação com o meio externo. Ambos os axiomas se articulam na formulação do conceito de ambientes e produtos homeodinâmicos, com vistas a ações projetuais que assegurem respostas neuropsicofisiológicas e cognitivo- comportamentais consistentes à saúde e ao bem-estar do ser humano. A próxima seção é dedicada ao aprofundamento deste conceito.

\section{Da homeostasia aos ambientes e produtos homeodinâmicos}

A homeostasia [homeo-, similar + stasis, condição] consiste em um conjunto de processos de regulação metabólica e, ao mesmo tempo, no estado resultante desta regulação. Todos os organismos vivos contam com dispositivos dedicados ao processo de regulação da vida. Este processo é automático e envolve lidar com toda sorte de problemas relacionados à sobrevivência, como: buscar fontes de energia, incorporá-las e transformá-las; preservar seu equilíbrio químico; e atuar na defesa do organismo, nos casos de lesão física ou doença (DAMÁsIO, 2004). Assim, a homeostasia se refere ao processo biológico dedicado a manter o ambiente interno do organismo dentro de estreitos limites fisiológicos (BEAR et al., 2017). Ou seja, consiste na capacidade do corpo em assegurar a sua estabilidade interna. A concepção de meio interno associado ao corpo é proposta em meados do século XIX, nos estudos experimentais realizados pelo médico francês Claude Ber- 
nard. Em suas investigações, Bernard identifica a estabilidade de diversos parâmetros fisiológicos, tais como: a temperatura do corpo, o batimento cardíaco e a pressão sanguínea. Tal estabilidade é também compreendida como 'a constância do meio interior'. Este entendimento, amplamente discutido por outros médicos e fisiologistas do seu tempo, culmina em 1929 na formulação do termo 'homeostase', realizada pelo fisiologista americano Walter B. Cannon para descrever a regulação deste meio interno.

A homeostase proposta por Cannon (1929) refere-se à manutenção de uma 'condição similar' ou, ainda, a 'um meio interno relativamente constante'. Isso se explica na escolha do prefixo 'homeo' [o meio interno é mantido dentro de uma amplitude de valores, e não em um valor fixo exato], e do sufixo 'stasis' [uma condição, e não um estado - que se mostra estático e invariável]. No âmbito desta formulação, Cannon propõe parâmetros homeostáticos, ou seja, indicadores que estão sob o controle dessa regulação interna, a saber: [a] fatores ambientais que afetam as células (osmolaridade, temperatura e $\mathrm{pH}$ ); [b] materiais para as necessidades da célula (nutrientes, água, sódio, cálcio, outros íons inorgânicos, oxigênio); [c] secreções internas com efeito contínuo e geral (hormônios e outras substâncias químicas, que as células utilizam para se comunicar umas com as outras). Cannon também postula quatro propriedades da homeostase: [1] o papel do sistema nervoso na preservação do 'ajuste' ao ambiente interno; [2] o conceito de nível tônico de atividade [tonos, tom]; [3] o conceito de controles antagonistas; [4] o conceito de que os sinais químicos podem possuir efeitos distintos em diferentes tecidos do corpo. Tanto os parâmetros, quanto as propriedades propostas por Cannon neste contexto são validadas em pesquisas posteriores (SILVERTHORN, 2003).

Desta perspectiva, podemos entender a homeostase como "um processo contínuo que envolve o monitoramento de múltiplos parâmetros, acompanhado da coordenação de respostas adequadas para minimizar qualquer distúrbio" (Ibidem, p.169). Em outras palavras, as reações homeostáticas detectam dificuldades ou oportunidades e, por meio de ações executadas no e/ou pelo corpo, resolvem o problema de eliminar as dificuldades ou aproveitar as oportunidades (DAMÁSIO, 2004). Os reflexos homeostáticos ocorrem em muitos níveis do sistema nervoso (BEAR et al., 2017), e suas respostas são localizadas ou sistêmicas. Quando localizadas, estas respostas alcançam regiões pontuais no corpo, e quando sistêmicas, atuam sobre o corpo todo. E, independente da resposta ser localizada ou sistêmica, este processo se elabora em três instâncias: [i] um estímulo ou mudança de condição; [ii] uma célula ou tecido que avaliam este estímulo e iniciam uma resposta; e [iii] as células ou tecidos que efetuam a resposta (SILVERTHORN, 2003). Nestas instâncias, qualquer distúrbio induz o organismo a buscar meios de compensação. Seja o distúrbio causado por estímulos negativos, advindos do meio interno ou externo ao corpo, seja por 
quadro clínico temporário ou permanente. Quando esta compensação mostra-se satisfatória, a homeostasia é restaurada; quando não, o desequilíbrio homeostático se instaura, e as respostas metabólicas geradas pelo corpo se alinham a este desequilíbrio. Neste momento, o corpo sinaliza a ausência de equilíbrio homeostático com emoções e sentimentos de valência negativa, como por exemplo estresse, medo, fadiga, tristeza, ansiedade (DAMÁSIO, 2004; ZUANON et al., 2019). Posteriormente, a doença se instala.

Esta busca por compensação para que o equilíbrio interno do corpo seja restabelecido indica "o processo de procura de um ajustamento, e não um ponto fixo de equilíbrio" (DAMÁSIO, 2004, p. 312). Este entendimento se alinha à formulação "homeodinâmica", introduzida por Rose (1998) em substituição ao termo "homeostasia". Ou seja, pela perspectiva da homeodinâmica, os processos de regulação da vida, e o decorrente equilíbrio alcançado, se elaboram em um fluxo dinâmico e em contínua transformação, diferente da possível ideia de um equilíbrio fixo e imutável. Alinhado a esta perspectiva, está o conceito dos "Ambientes e Produtos Homeodinâmicos", cunhado pelos cofundadores da Rede de Cooperação Transdisciplinar em Pesquisa e Inovação DASMind | UNICAMP [Design, Art, Space and Mind] ${ }^{1}$, também autores deste artigo. $O$ referido conceito é sediado nos campos das artes, da arquitetura, do urbanismo, e do design, e parte de uma abordagem transdisciplinar e complexa, para compreender a concepção, o projeto, o planejamento, o desenvolvimento e a implantação de ambientes arquitetônicos e urbanos, bem como de produtos físicos e/ou digitais, em profunda sinergia com a esfera corpo-mente-espiritualidade dos indivíduos, que habitam e usam tais espaços e objetos. Trata-se de assumir os ambientes e os objetos como importantes atores nesse contínuo e dinâmico processo de ajustamento interno do corpo. Como instrumentos homeodinâmicos, estes ambientes e produtos, para além de uma participação passiva na vida humana, são projetados para atuar de modo consistente e dinâmico sobre o organismo humano. Em outras palavras, são ambientes e produtos que podem contribuir ao alcance do equilíbrio homeodinâmico e, portanto, à saúde e ao bem estar do ser humano. Neste sentido, os ambientes e os produtos homeodinâmicos não somente englobam os conceitos de humanização e de ambiência humanizada. Eles consideram, ainda, as contribuições advindas de outros campos do conhecimento, como: neurociência aplicada à arquitetura; espaços restauradores; psicologia ambiental, biofilia, entre outros importantes estudos circunscritos na relação corpo-ambiente. Mais que isso, eles os aprofundam aos níveis de descrição da neuropsicofisiologia e da espiritualidade. Ambos os níveis corroboram com índices capazes de traduzir uma vida bem equilibrada e bem intencionada. Importante esclarecer que a espiritualidade é aqui abordada da sua perspectiva mental e não religiosa. Enquanto processo biológico de alta complexidade, a esfera espiritual é capaz de proporcionar ao organismo humano experiências de intensa har- 
monia, e deflagrar, por exemplo, sentimentos de alegria, geralmente serena, empatia, generosidade, amabilidade. Expressão mental da regulação homeodinâmica, estes sentimentos são capazes de agregar contribuições à saúde e ao bem-estar dos indivíduos que os experienciam (DAMÁSIO, 2004).

Para acessar estes níveis de descrição, e torná-los visíveis à ação projetual, as biointerfaces inteligentes (ZUANON, 2013-2011) mostram-se essenciais. Como dispositivos sensíveis, estas biointerfaces operam como agentes de mediações estáveis entre corpo-mente-cérebro-ambiente, com vistas ao equilíbrio homeodinâmico do organismo humano. Como órgãos sensoriais inorgânicos, as biointerfaces inteligentes são capazes de desconstruir e de ressignificar os modos usuais da percepção humana, e podem desempenhar múltiplos papéis, em alternância ou simultaneidade aos realizados pelos órgãos sensoriais orgânicos. Esses papéis são capazes de esclarecer, filtrar, reabilitar, ampliar, e/ou integrar dimensões e funções corporais. Como mediadoras, as biointerfaces inteligentes ainda propiciam uma condição diferenciada de interação: interações orgânicas, regidas pelo próprio organismo do indivíduo, pela condição emocional e neuropsicofisiológica que o seu corpo apresenta no momento específico daquela interação, seja com um ambiente ou produto. Em outras palavras, as biointerfaces inteligentes viabilizam a tradução de informações biológicas e neuropsicofisiológicas em dados digitais e, assim, proporcionam toda sorte de interações do organismo humano com ambientes arquitetônicos, ambientes urbanos, e produtos físicos e/ou digitais. No âmbito dos ambientes e produtos homeodinâmicos, a aplicação das biointerfaces inteligentes é relevante, tanto na fase de validação de parâmetros projetuais consistentes à regulação homeodinâmica, quanto como requisito projetual para viabilizar a comunicação afetiva entre o ambiente/produto e o estado da vida do organismo do usuário, com vistas ao seu equilíbrio homeodinâmico. Já os potenciais contextos e aplicações dos ambientes e produtos homeodinâmicos serão demonstradas a seguir. 


\section{Ambientes e Produtos Homeodinâmicos: potenciais contextos e aplicações}

Como já mencionado, os 'Ambientes e Produtos Homeodinâmicos' estão amparados numa base teórico-prática transdisciplinar e complexa, focada na relação indissociada entre o corpo, a mente e a espiritualidade. A palavra complexo, que consta na estrutura do conceito aqui exposto, tem sua origem no latim complexus e significa "tecer em conjunto". Ou seja, algo que está apto a reunir, contextualizar, globalizar e, ao mesmo tempo, reconhecer o singular, o individual e o concreto. Neste sentido, os 'Ambientes e Produtos Homeodinâmicos' "tecem em conjunto" com as contribuições advindas de distintas áreas do conhecimento e, assim, se consolidam como um conceito aberto e integrador, frente às exigências para a existência e para a sobrevivência nas sociedades contemporâneas.

A partir dessa visão complexa e transdisciplinar (MORIN, 19992005; FERREIRA, 2011-2014; FERREIRA et al., 2014) é possível compreender o ambiente e o corpo humano como instâncias integradas, que estabelecem trocas em fluxos contínuos e inter-relacionados. As adversidades vividas diariamente como problemas no trabalho, estresse, relacionamento afetivo, lembranças, emoções e sentimentos, não podem ser dissociadas do ambiente onde foram vivenciadas. De uma vez por todas, é preciso aceitar a impossibilidade de analisar a parte separada do todo. Não se pode mais separar a razão da emoção, a ciência das artes, a matéria da espiritualidade, ou o ambiente do corpo que o habita e o utiliza. Segundo o médico cardiologista Fábio Santos (SANTOS E PIMENTEL, 2020), áreas profissionais aparentemente separadas integram-se, para contribuir transdisciplinarmente com a saúde e com o bem estar de toda uma sociedade.

\footnotetext{
"O que me chamou muita atenção foi constatar que uma instituição como Harvard, uma das mais científicas e conceituadas, estava discutindo acaloradamente medicina e espiritualidade, por exemplo. Até mesmo eu ainda era incrédulo quanto a isso. Eles discutiam meditação e como um caminhar meditativo no meio do dia poderia ser favorável à sua saúde, dentro do espectro mens sana in corpore sano, ou seja, uma mente sã ajuda um corpo a se manter são. Estou falando de discussões no início deste novo século. Já estava mais do que na hora de entender essas correlações." (SANTOS E PIMENTEL, 2020, p.15)
}

A visão transdisciplinar e complexa dos 'Ambientes e Produtos Homeodinâmicos' ainda se amplia aos potenciais contextos e aplicações deste conceito. Para compreender esta extensão, inicialmente, faz-se necessário 
compreender as duas dimensões que o compõem: [1] Ambientes/Produtos Homeodinâmicos Preventivos; e [2] Ambientes/Produtos Homeodinâmicos Restauradores (Quadro 1). Importante ressaltar que esta divisão é aqui realizada apenas com o objetivo de facilitar a assimilação de seus propósitos. Na prática, essas dimensões interagem e, portanto, prevenção e restauração podem compor o intuito do mesmo ambiente/produto homeodinâmico.

Quadro 1. Itens do texto e seus respectivos estilos de parágrafo Fonte: Os autores, 2020

\section{$\rightarrow$ Preventivos}

Conceito

Ambientes e Produto Homeodinâmicos

$\rightarrow$ Restauradores

Os 'Ambientes e Produtos Homeodinâmicos Preventivos' têm como princípio a aquisição e a manutenção da saúde, a partir do hábito saudável, com o objetivo de alcançar e preservar o equilíbrio do corpo, da mente e do espírito. Esta dimensão visa promover a substituição de hábitos pouco saudáveis para hábitos saudáveis. Toma como principais referências os estudos da medicina preventiva e da filosofia da medicina do estilo de vida, áreas do conhecimento voltadas ao princípio da aquisição e da manutenção da saúde, e não somente ao tratamento de doenças. Neste âmbito, importantes centros de pesquisa se destacam, como: o Colégio Americano de Medicina do Estilo de Vida; a Associação Brasileira e Latino-Americana, sob a filosofia da Medicina do Estilo de Vida; o International Board of Lifestyle Medicine (IBLM); o Lifestyle Medicine Global Alliance (LMGA); o Institute for Functional Medicine (IFM), com o grupo: Mind and Body Institute, de Harvard; entre outros pelo mundo.

\footnotetext{
"Que os tradicionalistas não me escutem, mas Platão já dizia que o grande erro médico era separar o corpo do espírito durante o tratamento. Reforço isso apenas para colocar que a Medicina do Estilo de Vida não é uma nova medicina nem um conceito novo. É simplesmente o reforço dos estudos que bem conhecemos de que estudos apontam que $80 \%$ das doenças crônicas não transmissíveis (DCNT) podem ter seu caminho mudado - e melhores resultados no tratamento - se os hábitos do paciente forem alterados. Estamos falando de condutas preventivas tomadas ativamente. Pois a palavra-chave que me guiou à Medicina do estilo de Vida foi a prevenção." (SANTOS E PIMENTEL, 2020, p.13)
} 
Além da relação indissociada entre corpo, mente e espiritualidade, os 'Ambientes e Produtos Homeodinâmicos Preventivos' atuam em conjunto com a medicina preventiva para estimular a aquisição de hábitos saudáveis e de condutas preventivas, que contribuam à saúde e ao bem-estar dos indivíduos que habitam/utilizam estes ambientes/produtos. Para nortear este objetivo, quatro diretrizes são propostas como principais: [1] Projetar/ planejar ambientes/produtos direcionados à saúde e ao bem-estar, e não somente ao tratamento de doenças; [2] Compreender a individualidade e as necessidades de cada pessoa/grupo, para incorporá-los ao projeto/planejamento de ambientes/produtos que estimulem hábitos saudáveis; [3] Ser receptivo às contribuições advindas de distintas áreas do conhecimento, de modo a promover abordagens transdisciplinares à saúde e ao bem-estar; [4] Assegurar o envolvimento do público-alvo no processo de projeto/planejamento dos ambientes/produtos (FREIRE et al., 2018).

Longe de esgotar a totalidade das diretrizes norteadoras dos 'Ambientes e Produtos Homeodinâmicos Preventivos', este escopo mostra-se aqui suficiente para ilustrar alguns contextos de suas aplicações: [a] ambientes/produtos direcionados a estimular uma dieta equilibrada e saudável, sem uso de agrotóxicos e com alto poder de nutrição. Ou seja, com alternativas projetuais que valorizem uma dieta focada e rica em alimentos naturais, integrais e orgânicos. Neste sentido, desestimulam o consumo de alimentos processados e embalados, fonte de produtos químicos/tóxicos. Como exemplo, a inclusão de hortas orgânicas no projeto do ambiente podem estimular o maior consumo de produtos naturais, sem químicos e agrotóxicos; [b] ambientes/produtos capazes de estimular a movimentação corporal. Os movimentos corporais realizados durante as atividades diárias contribuem ao fortalecimento muscular e ao bom funcionamento do organismo. Assim, propostas projetuais que desestimulam o emprego excessivo dos recursos de automatização, e estimulam a movimentação natural do corpo são cruciais. A título de exemplo, mobiliários modulares/ articuláveis que propiciam diferentes composições e motivam a ação física; [c] ambientes/produtos dedicados a incentivar o exercício físico. Diferente do item acima, que apenas estimula o ato rotineiro de movimentar o corpo, ambientes/produtos que encorajam a realização de exercícios físicos são fundamentais para o desenvolvimento de hábitos saudáveis. Como exemplo, produtos dirigidos a exercícios físicos que, incorporados ao ambiente, despertam o entusiasmo à execução destas atividades; [d] ambientes/ produtos focados em minimizar o estresse do dia-a-dia. $O$ estresse, como uma das doenças deste século, causa desequilíbrio em todo o corpo. Neste sentido, direcionamentos projetuais que contribuam à retomada do equilíbrio interno do corpo, desestabilizado em virtude do estresse, é de suma importância à vida contemporânea. Como exemplo, ambientes/produtos que promovam o contato com a natureza, como plantas, hortas, animais 
e jardins, auxiliam o equilíbrio homeodinâmico do organismo humano; [e] ambientes/produtos voltados a favorecer o relaxamento e o desenvolvimento da espiritualidade. Como demonstrado, o relaxamento do corpo e da mente contribuem com a prevenção de diversas doenças. A título de exemplo, ambientes/produtos que propiciam a 'descompressão' por meio de estímulos somatossensoriais (iluminação, cor, aromas, texturas, sons), auxiliam o relaxamento do corpo e da mente, e se mostram fundamentais para a consolidação de hábitos saudáveis; [f] ambientes/produtos dirigidos aos cuidados do sono. Na medicina, os estudos sobre o sono avançam com rapidez. Isso se deve à importância do sono para a saúde e o bem-estar do ser humano. Para exemplificar, ambientes/produtos dirigidos à regulação do ritmo circadiano ${ }^{2}$ asseguram o sono consistente e a prevenção de diversas doenças; [g] ambientes/produtos orientados ao conforto ambiental acústico, térmico e lumínico. $O$ conforto ambiental é premissa à promoção do equilíbrio homeodinâmico do organismo humano. Exemplo disso, são os ambientes/produtos que propiciam acesso à adequada ventilação, acústica e iluminação natural/artificial. [h] ambientes/produtos atóxicos. É notória a variedade de materiais e produtos tóxicos que permeia a vida contemporânea. Ainda que invisível a olho nú, esta toxicidade distribuída nos materiais e objetos, a médio e a longo prazo, traz impactos severos à saúde humana. Neste sentido, é crucial privilegiar escolhas projetuais no desenvolvimento de ambientes/produtos que empreguem soluções atóxicas, como: livres de retardantes de chamas (já proibidas em inúmeros países); e isentas de elementos químicos tóxicos (que podem estar presentes em tintas; revestimentos; soluções impermeabilizantes, antiaderentes, de limpeza, entre tantos outros).

Já no que concerne aos 'Ambientes e Produtos Homeodinâmicos Restauradores', estes têm como princípio a restauração da saúde e do bem-estar de pessoas com algum tipo de doença (morbidades ou comorbidades) e/ou de distúrbio do corpo/mente. Esta dimensão visa soluções projetuais que atuem e tragam benefícios ao organismo debilitado, em auxílio aos tratamentos farmacológicos destas doenças/distúrbios. Para tanto, na sua base transdisciplinar e complexa, articula principalmente contribuições da neurociência cognitivo-comportamental e dos espaços e ambiências humanizadas, com vistas à restauração do equilíbrio do corpo, da mente e do espírito.

Importante salientar que as potenciais aplicações já descritas no âmbito dos 'Ambientes e Produtos Homeodinâmicos Preventivos' se estendem e se adequam aos objetivos e às particularidades de cada 'Ambiente e Produto Homeodinâmico Restaurador'. Cabe aqui, então, destacar alguns de seus possíveis contextos de atuação: [i] hospitais: com ambientes/produtos que contribuam à uma recuperação clínica mais rápida, e consequente redução do tempo de internação e do risco de infecção hospitalar; [ii] ambientes educacionais para indivíduos com síndromes: com ambientes/ produtos que favoreçam a atenção, a concentração, a criatividade, a conso- 
lidação e a evocação do conhecimento adquirido; [iii] clínicas de cuidados: com ambientes/produtos que contribuam à estabilização do avanço e à redução dos sintomas de doenças degenerativas, como o Alzheimer (ZUANON E FARIA, 2018; FARIA E ZUANON, 2019); à atenuação dos quadros clínicos de depressão em idosos ou em pacientes psiquiátricos; dentre diversos outros.

Cabe, ainda, reiterar o papel fundamental das biointerfaces inteligentes em ambas as dimensões 'Preventiva' e 'Restauradora' dos 'Ambientes e Produtos Homeodinâmicos'. Com as biointerfaces, estes ambientes/ produtos ganham 'inteligência' e são capazes de identificar a condição neuropsicofisiológica dos indivíduos que os habitam/utilizam e, assim, entregar em tempo real estímulos somatossensoriais e sensório-motores coerentes à condição neuropsicofisiológica identificada. Ou seja, tais estímulos respondem de modo afetivo ao organismo humano e, com isso, corroboram ao seu equilíbrio homeodinâmico, à prevenção de doenças e à restauração da sua saúde e bem-estar.

Em tempo, vale recuperar que os domínios das artes, da arquitetura, do urbanismo, e do design constituem o alicerce, transdisciplinar e complexo, que orienta a continuidade e a identificação de outros estudos, contextos e aplicações capazes de ampliar o escopo destes ambientes/produtos (Fig. 1).

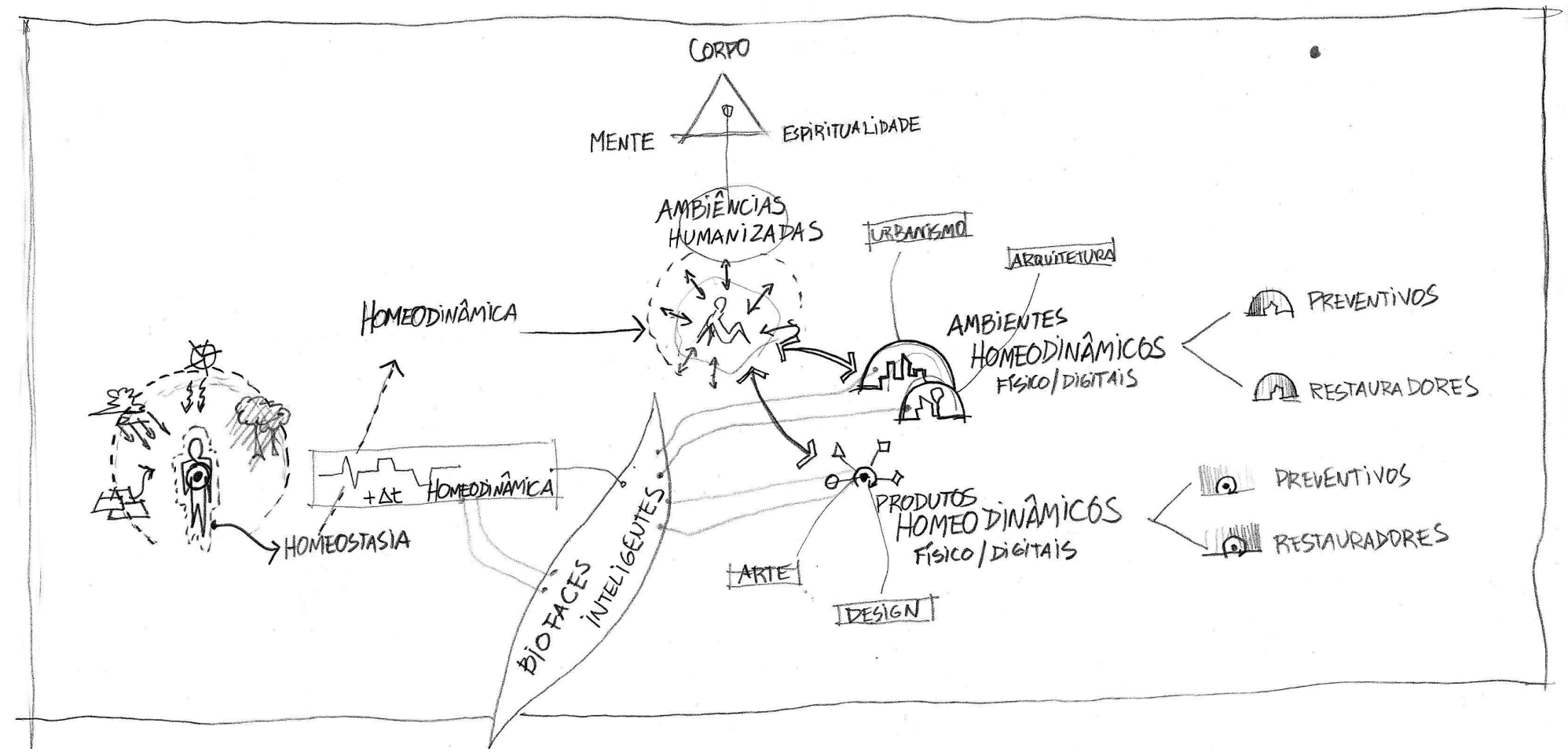

Fig 1. Síntese do conceito ‘Ambientes e Produtos Homeodinâmicos': abordagem transdisciplinar e complexa, relaciona corpo-mente-espiritualidade, a partir das dimensões preventiva-restauradora, mediadas pelas biointerfaces inteligentes.

Fonte: Os autores, 2020 
Com este entendimento, é possível avançar à descrição dos três eixos que guiam as aplicações do conceito 'Ambientes e Produtos Homeodinâmicos': [1] Ambientes Arquitetônicos Homeodinâmicos; [2] Ambientes Urbanos Homeodinâmicos; [3] Produto Homeodinâmico Físico e/ou Digital.

Os 'Ambientes Arquitetônicos Homeodinâmicos', preventivos e/ ou restauradores, referem-se ao conceito aplicado no estudo, no planejamento, no projeto e na construção de ambientes arquitetônicos. Este eixo visa analisar e compreender os ambientes do usuário, seja residencial, educacional, cultural, corporativo, comercial, entre outros, na relação corpo, mente, espiritualidade. Seja na instância projetual ou física, evidencia a cooperação entre os elementos arquitetônicos e o organismo humano, para o restabelecimento do equilíbrio homeodinâmico do corpo, com vistas à sua saúde e ao seu bem-estar. Associado às biointerfaces inteligentes (ZUANON, 2013-2011), este eixo também avalia e atesta o nível da qualidade homeodinâmica dos ambientes nas suas diversas finalidades: cuidados; cura; trabalho; troca de conhecimentos; lazer; entre outros. Com esta avaliação, formula a proposição de soluções projetuais adequadas ao equilíbrio interno do corpo dos seus usuários, em alinhamento ao propósito de cada ambiente.

Os 'Ambientes Urbanos Homeodinâmicos' têm como suporte os tecidos urbanos, embora não necessariamente representem uma simples mudança de escala, da escala arquitetônica para a escala urbana. Ou seja, refletir sobre as relações que buscam a prevenção ou a restauração da saúde e do bem estar do indivíduo, enquanto habitante ou usuário da cidade, em muitos casos se dá na própria escala do desenho urbano, no interstício dos edifícios, nas áreas verdes, nas pequenas praças e em outros ambientes urbanos abertos (ZUANON et al., 2020). Este eixo sinaliza inclusive uma revisitação aos urbanistas clássicos que, pioneiramente, se debruçaram sobre a percepção espacial, e as relações de territorialidade, privacidade, personalização e crowding (MONTEIRO e TURCZYN, 2018). Os diversos estudos de humanização também trazem fundamentos valiosos aos 'Ambientes Urbanos Homeodinâmicos' que, aliados às biointerfaces inteligentes (ZUANON, 2013-2011), transferem importantes contributos à configuração de cidades saudáveis.

Os 'Produtos Homeodinâmicos', preventivos e/ou restauradores, envolvem os estudos, o projeto e o desenvolvimento de produtos físicos, digitais e/ou físico-digitais capazes de 'sentir' e 'reagir' em tempo real e com empatia à condição neuropsicofisiológico do seu usuário, sem interromper o desempenho de suas atividades rotineiras. Este eixo atua em profunda convergência com as biointerfaces inteligentes (ZUANON, 20132011). Neste sentido, correlaciona contribuições da computação afetiva, da computação cognitiva, da visão computacional, e da computação vestível à base transdisciplinar e complexa do seu conceito. Nessa íntima conexão com o organismo humano, os produtos homeodinâmicos propiciam o acesso e a interação com a escala neurobiológica dos afetos, emoções 
e sentimentos, durante distintas experiências centradas no ser humano, sejam elas vivenciadas em ambientes arquitetônicos ou urbanos. Ainda, viabilizam a interpretação consistente das condições globais do corpo, em resposta aos estímulos somatossensoriais e sensório-motores produzidos por estes ambientes.

Assim, ao estabelecerem uma relação direta com o organismo humano, os 'Ambientes e Produtos Homeodinâmicos', sejam eles preventivos e/ou restauradores, nas suas escalas arquitetônica, urbana e do objeto, mostram extrema relevância à regulação da vida e à sobrevivência, tanto nos contextos sociais atuais, quanto futuros.

\section{Considerações Finais}

Marcado por enormes desafios, o momento contemporâneo pode também ser compreendido como um período histórico de ricas e incontáveis possibilidades dirigidas ao desenvolvimento humano, em todas as suas esferas. A civilização humana logrou evolução em praticamente todas as áreas do conhecimento e, agora, cientes dos imperativos transdisciplinares e complexos, avançamos com a proposição do conceito 'Ambientes e Produtos Homeodinâmicos' para compreender a relação ambiente-produto-organismo humano, a partir da conexão indissociável entre corpo, mente e espiritualidade.

É importante destacar que a ciência, por meio dos seus campos de atuação, sempre contribuiu para a saúde humana. Desse consistente legado, estudos nas áreas da neurociência cognitivo-comportamental, dos espaços e ambiências humanizadas, da medicina preventiva, da filosofia da medicina do estilo de vida, e das biointerfaces inteligentes têm convergido e resultado em um profundo conhecimento do ser humano: suas necessidades básicas e complexas; os fatores que afetam sua saúde, seu bem-estar e o seu estado de espírito; e suas inter-relações com o ambiente, a natureza e o planeta. Neste alinhamento, estão as propostas inovadoras e as novas abordagens conceituais e metodológicas que, por meio do pensar e do fazer projetual, buscam responder de forma sustentável aos anseios de nossa espécie por equilíbrio físico, mental e espiritual, como a exposta ao longo deste artigo.

Assim, propor o conceito e os potenciais contextos e aplicações dos 'Ambientes e Produtos Homeodinâmicos', Preventivos e Restauradores, nas escalas arquitetônica, urbana e do objeto, significa responder de modo consistente e perene a estes anseios. Em perspectiva transdisciplinar e complexa, isso se coaduna aos demais esforços científicos, cujo objetivo primordial é o contínuo aprimoramento da relação ambiente-produto-organismo humano. 
1 A Rede de Cooperação Transdisciplinar em Pesquisa e Inovação DASMind I UNICAMP [Design, Art, Space and Mind] dedica-se a investigações teóricas e aplicadas nos campos transdisciplinares da Arquitetura, do Urbanismo, do Design e da Arte, relacionados às áreas das Ciências Cognitivas, Neurociências, Inteligência Artificial, Ciências da Saúde e Educação. Mais informações em: https://www.iar.unicamp.br/dasmind. 20 ritmo circadiano desempenha o papel de relógio biológico que, mesmo na ausência de luz, mantém nossas funções neurofisiológicas minimamente reguladas por um período aproximado de 24 horas (LEGATES et al., 2014).

\section{Referências}

BARROS, R.; KOWALTOWSKI, Doris C. C. K. Do projeto urbano ao detalhe construtivo: "A Pattern Language" finalmente traduzida. 2013. Disponível em: https://www.vitruvius.com. br/revistas/read/resenhasonline/12.137/4734. Acesso em: 22 jun. 2020.

BEAR, M. F; CONNORS, B. W; PARADISO, M. A. Neurociências - Desvendando o sistema nervoso. São Paulo: Artmed., 4a edição, 2017.

CAVALCANTI, P. B.; AZEVEDO, G. A. N.; DUARTE, C. R. Humanização, imagem e caráter dos espaços de saúde. Cadernos PROARQ, Rio de Janeiro, v. 11, p. 7-10, 2007.

CANNON, W. B. Organization for Physiological Homeostasis, Physiological Reviews 9:339443, 1929.

DAMÁSIO, A. R. E o cérebro criou o Homem. Tradução: Laura Teixeira Motta. São Paulo: Companhia da Letras, 2011.

DAMÁSIO, A. R. Em busca de Espinosa: prazer e dor na ciência dos sentimentos. Tradução: Laura Teixeira Motta. São Paulo: Companhia das Letras, 2004.

DUARTE, C. R. Ambiência: por uma ciência do olhar sensível no espaço. In: THIBAUD, J. P.; DUARTE, C. R. (orgs.). Por une écologie sociale de la ville sensible: ambiences urbaines en partage. Genève: MetisPresses, v. 1, 2013.

FARIA, B. A. C.; ZUANON, R. Architecture-Neuroscience cooperation: project recommendations to therapeutic gardens design for the non-pharmacological treatment of individuals with Alzheimer's disease. Lecture Notes in Computer Science, v. 11582, p. 181-199, 2019.

FERREIRA C. L. A obra de design brasileiro dos Irmãos Campana sob o olhar das relações complexas. Campinas, Brasil: Tese de Doutorado, Instituto de Artes, Universidade Estadual de Campinas-UNICAMP, 2011.

FERREIRA C. L. O design contemporâneo brasileiro e sua complexidade. Águas de São Pedro: Livronovo, 2014. 
FERREIRA, C. L.; LONA, M. T. ; CHIMIRRA, V. . Irmãos Campana: A concepção projetual no design brasileiro. In: Luisa Paraguai; Rachel Zuanon. (Org.). Design, Arte e Tecnologia - DAT 9. 1ed. São Paulo: Rosari, v. 1, p. 31-49, 2014.

FREIRE, R. A.; MONTEIRO, E. Z.; FERREIRA, C. L. . Challenges of Open Design - from theory to practice. DAT Design, Art \& Technology, v. 3, p. 353-391, 2018.

KOHLSDORF G.; KOHLSDORF, M. E. Ensaio sobre o desempenho morfológico dos lugares. Brasília: FRBH, 2017.

KOWALTOWSKI, D. C. C. Aesthetics and Self-Built Houses: an Analysis of a Brazilian Setting. Habitat Internacional, [s.l.], v. 22, n. 3, p. 299-312, 1998.

LEGATES, T.; FERNANDEZ, D.; HATTAR, S. Light as a central modulator of circadian rhythms, sleep and affect. Nat Rev Neurosci 15, 443-454, 2014.

LEITNER, A. D.; PINA, S. M. Arquitetura sob a ótica da humanização em ambientes de quimioterapia pediátrica. Ambiente Construído, Porto Alegre, v. 20, n. 3, p. 179-198, jul./ set. 2020.

LUKIANTCHUKI, M. A.; SOUZA, G. B. Humanização da arquitetura hospitalar: entre ensaios de definições e materializações híbridas. Arquitextos, [s.l.], v. 118, n. 1, mar. 2010. Disponível em: https://www.vitruvius. com.br/revistas/read/arquitextos/10.118/3372. Acesso em: 14 jul. 2020. MALARD, Maria Lúcia. Os objetos do quotidiano e a ambiência. $2^{\circ}$ Encontro Nacional de Conforto no Ambiente Construído, v. 2, p. 359-361, 1993.

MONTEIRO, E. Z.; TURCZYN, D. T. The five categories of solá-morales as a legacy for reading the urban landscape. Architecture, City and Environment, v. 12, p. 73-90, 2018. MORIN, E. Introdução ao pensamento complexo. Porto Alegre: Sulina, 2005. MORIN, E. La tête bien faite. Repenser la réforme - Réformer la pensée. En Collection "L 'Histoire Immediate". (pp.18). Paris: Éditions du Seuil, 1999.

PALLASMAA, J. A imagem corporificada - imaginação e imaginário na arquitetura. Porto Alegre: Bookman, 2013.

POL, E. Seis reflexiones sobre los procesos psicologicos en el uso, organizacion y evaluacion del espacio. In: Amérigo, M.; Aragonés, J.I. \&. Corraliza, J. (Orgs.), El comportamiento en el medio natural y construido. Badajoz: Junta de Extremadura, 1992. ROSE, S. Lifelines: Biology beyond Determinism. Nova York: Oxford University Press,1998. SANTOS, F. C.; PIMENTEL L. C. Manual do Estilo de Vida. São Paulo: nVersos, 2020.

SILVERTHORN, D. U. Fisiologia Humana: uma abordagem integrada. São Paulo: Manole, 2a edição, 2003.

THIBAUD, J.P. (2004). 0 ambiente sensorial das cidades: para uma abordagem de ambiências urbanas. In E.T. Tassara; E.P. Rabinovich; M.C. Guedes (Orgs.). Psicologia e ambiente. SP: EDUC.347-361.

TUAN, Y. F. Topofilia: um estudo da percepção, atitudes e valores do meio ambiente. São Paulo: DIFEL, 1980.

TUAN, Y. F. Paisagens do Medo. São Paulo: Unesp, 2005.

ZUANON, R.; OLIVEIRA, M. R. DA S.; FERREIRA, C. L.; MONTEIRO, E. Z. Memória, emoções e sentimentos: impactos na percepção espacial e afetiva da área urbana central de Campinas. DAT Journal, v. 5, p. 4-21, 2020. 
ZUANON, R. Z; FERREIRA, C. L.; MONTEIRO, E. Z.; S.; BERNARDINI, S. P. Architecture in mind: elderlys affective memories and spatial perceptions of a downtown area. Lecture Notes in Computer Science, v. 1, p. 1, 2019.

ZUANON, R.; FARIA, B. A. C. Landscape Design and Neuroscience Cooperation: contributions to the non-pharmacological treatment of Alzheimer's disease. Lecture Notes in Computer Science, p. 353-374, 2018.

ZUANON, R. Designing Wearable Bio-Interfaces: Transdisciplinary Articulations between Design and Neuroscience. Lecture Notes in Computer Science, v. 8009, p. 689-699, 2013. ZUANON, R. Bio-Interfaces: designing wearable devices to organic interactions. In: Anna Ursyn (Org.). Biologically-Inspired Computing for the Arts: Scientific Data through Graphics. Pennsylvania: IGI Global, p. 1-17, 2011. 